\title{
The past, the present, and the future: reflecting on medical history as we welcome new leaders
}

As those of us in the UK swelter in unusual Mediterranean temperatures and (some) marvel at the unexpected prowess of our national football team, I hope you find the time to peruse your summer edition of Clin Med.

I write this the day after we have a new health secretary appointed after 5 years, and at a time when the next edition of this journal will be delivered under a new president of the RCP and newly appointed substantive editor-in-chief. I wish all of them success as they lead us forwards. This month three themes emerge: a reflection on the past, in this the RCP's 500th year; a focus on haematology (in CME, original research and reviews); and attention to common conditions we see in general medical practice (infection, ${ }^{1}$ atrial fibrillation, ${ }^{2}$ pulmonary embolism ${ }^{3}$ and inflammatory bowel disease ${ }^{4}$ ).

Usually lacking the space for historical articles (and mindful of my military partialities), I made an exception in this quincentennial year to commission a series of articles on the contribution of military medicine to NHS practice, the first of which is from the RAF Medical Services, delivered in their own centenary year. ${ }^{5}$ I personally am proud to be an RAF physician and have had the privilege to be involved in aeromedical evacuation throughout my career, including during the Ebola outbreak, but I am ashamed to say that I was blissfully unaware of the role my forbears played in both the development of renal replacement therapy and dialysis services and the commercial oxygen systems that are keeping me alive as I write this missive on a flight crossing the Atlantic. I look forward to learning what my Army and Royal Navy colleagues have contributed in the next few issues.

Haematology is a major focus of this edition, with excellent CME on haemostatic and anticoagulation issues ${ }^{6,7}$ and the emergence of autologous haematopoetic stem cell transplantation for advanced management of not just haematological malignancies, but other common conditions such as multiple sclerosis, systemic sclerosis and Crohns' disease. ${ }^{8,9}$ These articles provide a helpful and erudite summary of the issues general physicians face in an increasingly complex field. A thought-provoking article on blood donation from high-risk groups ${ }^{10}$ and elegant original research looking at improving the diagnostic accuracy of D-dimers in the ageing population ${ }^{4}$ and the long term thromboembolic risk associated AF in critical care ${ }^{3}$ are also included in this edition, as part of high-quality work written by medical students and trainees.

This latter point is one of the reasons I have been honoured to be the steward of this journal in my time as interim editor-in-chief. This is your journal, constructed with an intent to balance quality research, often written by early career colleagues, with specialist experts explaining the key advances in their complex subspeciality fields to those of us that work on acute un-selected medical takes. With clinical lessons, images and a focus on acute medical care also in the mix, there is no other journal aimed specifically at the jobbing physician. You will hopefully have received the survey asking your opinions on how we deliver the journals in the future (https://goo.gl/forms/ tF4vpBK6flZ0M5ro2) and you have until 17 August to share these with us. We are of course keen to exploit digital technology and we will very shortly move to a more agile and flexible publication platform that will allow ahead of print access; however, I am also cognisant that membership surveys have suggested that readers also value a hard copy of the journal. So please do let us know your views and help inform the future of this journal and the wider RCP publications. .

\section{References}

1 Powell N, McGraw-Allen K, Menzies A et al. Identifying antibiotic stewardship interventions to meet the NHS England CQUIN: an evaluation of antibiotic prescribing against published evidencebased antibiotic audit tools. Clin Med 2018;18:276-81.

2 Clayton B, Ball S, Read J, Waddy S. Risk of thromboembolism in patients developing critical illness-associated atrial fibrillation. Clin Med 2018;18:282-7.

3 Dutton J, Dachsel M, Crane R. Can the use of an age-adjusted D-dimer cut-off value help in our diagnosis of suspected pulmonary embolism? Clin Med 2018;18:293-6.

4 Philip V, Soubieres A, Poullis A. Health concerns associated with travelling with inflammatory bowel disease (IBD): a questionnaire survey. Clin Med 2018;18:288-92.

5 Posselt BN, Greenhalgh AM, Almond MK. 100 years of the Royal Air Force's contribution to medicine: providing care in the air and delivering care by air. Clin Med 2018;18:297-300.

6 Gulati D, Novak A, Stanworth SJ. Common haemostasis issues in major bleeding and critical illness. Clin Med 2018;18:320-3.

7 Thomas S, Makris M. The reversal of anticoagulation in clinical practice. Clin Med 2018;18:314-9.

8 Snowden JA, Sharrack B, Akil M et al. Autologous haematopoietic stem cell transplantation (aHSCT) for severe resistant autoimmune and inflammatory diseases - a guide for the generalist. Clin Med 2018;18:329-34.

9 Graham C, Hewitson R, Pagliuca A, Benjamin R. Cancer immunotherapy with CAR-T cells - behold the future. Clin Med 2018;18:324-8

10 Sturrock BRH, Mucklow S. What is the evidence for the change in the blood donation deferral period for high-risk groups and does it go far enough? Clin Med 2018;18:304-7.

Wing Commander Ed Nicol Editor-in-chief 